\title{
GLYCOPYRROLATE AND CARDIAC DYSRHYTHMIAS IN GERIATRIC PATIENTS AFTER REVERSAL OF NEUROMUSCULAR BLOCKADE
}

\author{
Stanley Muravchick, William D. Owens, and James A. Felts
}

THE SHORT-LIVED anticholinergic activity of intravenous atropine is poorly matched to the prolonged action of the anticholinesterase drugs used for antagonism of neuromuscular blockade. Although simultaneous injection of atropine can prevent neostigmine-induced or pyridostigmine-induced bradycardia initially, ${ }^{1,2}$ protection against cardiac muscarinic effects during the subsequent hours of the postoperative period may require a longer-acting anticholinergic such as glycopyrrolate. The purpose of this study was to determine the frequency of postoperative dysrhythmias following the use of glycopyrrolateanticholinesterase mixtures in geriatric patients with a high incidence of cardiovascular disease. The results will be compared with those obtained previously ${ }^{3}$ using atropine-anticholinesterase mixtures in a similar patient population.

\section{MethoDs}

Fifty patients 65 years of age or older undergoing elective surgery were observed for postoperative cardiac dysrhythmias. The Human Studies Committee of Washington University School of Medicine determined individual informed consent to be unnecessary for this study and none was obtained. Clinical considerations determined the anaesthetist's choice of anaesthetic agent and non-depolarizing muscle relaxant. At the end of the operation neuromuscular blockade was antagonized by either neostigmine, $0.07 \mathrm{mg} \cdot \mathrm{kg}$ intravenously (maximum $5 \mathrm{mg}$ ) or pyridostigmine $0.28 \mathrm{mg} \cdot \mathrm{kg}$ intravenously (maximum $20 \mathrm{mg}$ ). Glycopyrrolate $0.015 \mathrm{mg} \cdot \mathrm{kg}$ (maximum $1.2 \mathrm{mg}$ ) was given intravenously simultaneously with the anti-

Stanley Muravchick, M.D., Ph.D., Resident William D. Owens, M.D., Associate Professor James A. Felts, M.D., Assistant Professor

Department of Anesthesiology, Washington University School of Medicine, 660 South Euclid Avenue, St. Louis, Missouri, 63110.

Dr. Muravchick is currently Assistant Professor of Anesthesiology, University of Miami School of Medicine, P.O. Box 520875, Miami, FL 33152.

Study supported in part by a grant from the A.H. Robins Company, Richmond, Virginia. cholinesterase. No patient received atropine as part of these "reversal" mixtures. The dose schedule for the two anticholinesterase drugs was consistent with the estimates of relative potency reported by Miller, et $a{ }^{4}{ }^{4}$ Choice of anticholinesterases was determined by randomisation according to hospital admission number.

The electrocardiogram was monitored continuously by oscilloscope in the operating room and the recovery room for a period of 90 minutes following injection of the anticholinesterase-anticholinergic mixture. All cardiac dysrhythmias were documented by paper recording and evaluated by an anaesthesiologist. Criteria for a significant dysrhythmia were as follows: (1) heart rate greater than 100 per minute or less than 60 per minute: (2) electrocardiographic evidence of a conduction defect not observed preoperatively; or (3) a three-fold or greater increase in the frequency of any atrial or ventricular premature contractions noted preoperatively. Any dysrhythmia clearly related to arterial blood gas abnormality, electrolyte imbalance, hypertension, hypotension, or hypovolaemia was not considered to be a consequence of the anticholinesterase combination. All necessary laboratory specimens were obtained by the anaesthesiologist at the time of the dysrhythmias, and only patients with dysrhythmias not attributed to identifiable systemic disturbances were considered to have had anticholinesterase-related dysrhythmias. Appropriate treatment was administered as indicated by the patient's clinical status.

Diagnosis of pre-existing ischaemic heart disease was made on the basis of medical history and preoperative electrocardiogram. Continuing therapy with antihypertensive medications, a resting systolic blood pressure greater than 150 torr $(19.95 \mathrm{kPa})$ or a diastolic pressure greater than 100 torr $(13.3 \mathrm{kPa})$ were the criteria for the diagnosis of hypertensive peripheral vascular disease.

Statistical analysis was performed by calculation of chi-square values from contingency tables, using a Yates correction for continuity when appropriate. A " $P$ " value of less than 5 per cent established statistical significance. 
TABLE I

InCidence of Cardiac DysRhythmias By Patient Characteristics

\begin{tabular}{|c|c|c|c|c|c|c|}
\hline \multirow[b]{2}{*}{$\begin{array}{l}\text { 1. No known cardio- } \\
\text { vascular disease }\end{array}$} & \multicolumn{2}{|c|}{$\begin{array}{c}\text { With } \\
\text { neostigmine }\end{array}$} & \multicolumn{2}{|c|}{$\begin{array}{l}\text { With } \\
\text { pyridostigmine }\end{array}$} & \multicolumn{2}{|c|}{ Overall } \\
\hline & $(0 / 12)$ & $0 \%$ & $(0 / 8)$ & $0 \%$ & $(0 / 20)$ & $0 \% *$ \\
\hline $\begin{array}{l}\text { 2. Established cardio- } \\
\text { vascular disease }\end{array}$ & $(3 / 9)$ & $33 \%$ & $(5 / 21)$ & $24 \%$ & $(8 / 30)$ & $27 \% *$ \\
\hline $\begin{array}{l}\text { alone } \\
\text { (b) coronary artery }\end{array}$ & $(1 / 3)$ & $33 \%$ & $(2 / 7)$ & $29 \%$ & $(3 / 10)$ & $30 \%$ \\
\hline $\begin{array}{l}\text { disease alone } \\
\text { (c) both }\end{array}$ & $\begin{array}{l}(2 / 5) \\
(0 / 1)\end{array}$ & $\begin{array}{r}40 \% \\
0 \%\end{array}$ & $\begin{array}{r}(2 / 10) \\
(1 / 4)\end{array}$ & $\begin{array}{l}20 \% \\
25 \%\end{array}$ & $\begin{array}{r}(4 / 15) \\
(1 / 5)\end{array}$ & $\begin{array}{l}27 \% \\
20 \%\end{array}$ \\
\hline Totals & $(3 / 21)$ & $14 \%$ & $(5 / 29)$ & $17 \%$ & $(8 / 50)$ & $16 \%$ \\
\hline
\end{tabular}

*Significant difference $(P<0.05)$ in overall incidence between patients with and without established cardiovascular disease. All other comparisons showed no statistically significant differences $(\mathrm{P}>0.05)$.

TABLE II

Incidence of Cardiac Dysrhythmias By Anaesthetic Technique and Agents

\begin{tabular}{lrlllll}
\hline \hline & \multicolumn{1}{c}{$\begin{array}{c}\text { With } \\
\text { neostigmine }\end{array}$} & & $\begin{array}{c}\text { With } \\
\text { pyridostigmine }\end{array}$ & Overall \\
\hline $\begin{array}{l}\text { Intravenous (narcotic) } \\
\text { anaesthesia }\end{array}$ & $(2 / 13)$ & $15 \%$ & $(4 / 12)$ & $33 \%$ & $(6 / 25)$ & $24 \%$ \\
$\begin{array}{l}\text { Inhalation (halogenated) } \\
\quad \text { anaesthesia }\end{array}$ & $(1 / 8)$ & $13 \%$ & $(1 / 17)$ & $6 \%$ & $(2 / 25)$ & $8 \%$ \\
$\begin{array}{l}\text { Muscle relaxation with } \\
\text { d-tubocurarine }\end{array}$ & $(2 / 16)$ & $13 \%$ & $(2 / 16)$ & $13 \%$ & $(4 / 32)$ & $13 \%$ \\
$\begin{array}{l}\text { Muscle relaxation } \\
\text { with pancuronium }\end{array}$ & $(1 / 5)$ & $20 \%$ & $(3 / 13)$ & $23 \%$ & $(4 / 18)$ & $22 \%$ \\
$\quad$ Totals & $(3 / 21)$ & $14 \%$ & $(5 / 29)$ & $17 \%$ & $(8 / 50)$ & $16 \%$ \\
\hline
\end{tabular}

Differences between comparable groups were not statistically significant $(P>0.05)$.

\section{RESULTS}

In the 50 patients studied, the overall incidence of new cardiac dysrhythmias during recovery from anaesthesia, as defined above, was 16 per cent. In 21 patients, neuromuscular block was antagonized with the neostigmine-glycopyrrolate mixture ("neostigmine group"); in the remaining 29 patients, pyridostigmine-glycopyrrolate was used ("pyridostigmine group"). Dysrhythmias noted were sinus tachycardia (1), sinus bradycardia (1), premature atrial contractions with first degree heart block (1), wandering atrial pacemaker (1), and premature ventricular contractions (4). The time of onset of the dysrhythmias varied from 5 to 65 minutes after the injection of the anticholinesterase mixture, mean $27.4 \pm 23.3$ minutes ( \pm S.D.).
There was a statistically significant relationship between the occurrence of cardiac dysrhythmias in the postoperative period and preexisting cardiovascular disease. All observed dysrhythmias were in patients with known coronary artery disease with or without cardiac conduction defect, systemic hypertension, or a combination of these (Table I).

The incidence of dysrhythmias was not related to the choice of anaesthetic agents or to the use of pancuronium as compared to d-tubocurarine (Table II). Neither the anaesthetic technique nor the choice of muscle relaxants produced a significant difference in the observed incidence of dysrhythmias in patients given neostigmine as compared to those receiving pyridostigmine.

There was no significant difference between the neostigmine and pyridostigmine groups in the 
TABLE III

Distribution of Patients Between Anticholinesterase Groups

\begin{tabular}{lcc}
\hline \multicolumn{1}{c}{ Patients } & $\begin{array}{c}\text { Neostigmine } \\
\text { group }(\mathrm{n}=21)\end{array}$ & $\begin{array}{c}\text { Pyridostigmine } \\
\text { group (n = 29) }\end{array}$ \\
\hline $\begin{array}{l}\text { With age 75 years or greater } \\
\text { Classified ASA III or IV }\end{array}$ & 8 & 4 \\
Male:female & 11 & 9 \\
With no history of cardiovascular disease & 12 & $14: 15$ \\
With history of hypertensive peripheral & 3 & 8 \\
$\quad$ vascular disease & 5 & 7 \\
$\begin{array}{l}\text { With history of coronary artery disease } \\
\text { (with or without conduction defect) }\end{array}$ & & 10 \\
With history of both coronary artery and & 1 & 4 \\
hypertensive peripheral vascular disease & 1 & 7 \\
On continuing digoxin therapy & 8 & 17 \\
Receiving halogenated inhalation agents & $16: 5$ & $15: 14$ \\
\hline
\end{tabular}

Differences between comparable groups were not statistically significant $(P>0.05)$.

incidence of cardiac dysrhythmias (Table II). The mean doses of neostigmine and pyridostigmine given were $4.40 \pm 0.66$ and $17.46 \pm 2.92 \mathrm{mg}$, respectively. The mean dose of glycopyrrolate was $0.88 \pm 0.15 \mathrm{mg}$. Evaluation of the patients within these two groups revealed no statistically significant difference in distribution related to medical history, age, ASA physical status, sex, continuing use of digoxin, or the anaesthetic agents or relaxants used (Table III).

\section{Discussion}

Intravenous atropine provides an anticholinergic effect for 45 minutes, which is less than the average period of increased acetylcholine activity produced by either neostigmine or pyridostigmine (60 and 80 minutes, respectively)., Thus, when atropine is used for this purpose, the patient may be unprotected from potentially dangerous cardiac muscarinic phenomena (bradycardia and delayed A-V node conduction) during the period from 45 to 80 minutes following injection of the "reversal" mixture.

The major risk factors for cardiac dysrhythmias under these circumstances include the intensity of muscarinic activity produced by the anticholinesterase, the effectiveness of the anticholinergic agent in blocking muscarinic effects, discrepancy in duration of action between the anticholinesterase and the anticholinergic agent, and the type and severity of the patient's pre-existing myocardial disease. A prior study of geriatric patients by Owens, et al..$^{3}$ demonstrated a significantly greater incidence of postoperative dysrhythmias following neostigmine-atropine than after pyridostigmine-atropine ( 35 per cent and 14 per cent respectively). In view of the similar duration of action of the two anticholinesterase drugs, it was concluded that neostigmine appeared to have a more significant cardiac muscarinic effect than did pyridostigmine, a conclusion supported by earlier comparisons ${ }^{2,5-7}$ of the muscarinic properties of these two drugs. An additional observation was that patients with coronary artery disease, cardiac conduction defects, or hypertensive peripheral vascular disease had a significantly greater incidence of dysthythmias than patients of comparable age without known cardiovascular disease. ${ }^{3}$ The relatively young age and good health of the patients studied by Fogdall and Miller ${ }^{8}$ may explain their failure to demonstrate any clinical difference in muscarinic activity between the two anticholinesterases.

In the present study, with glycopyrrolate given as the anticholinergic agent according to a weight-specific dose schedule, the incidence of dysrhythmias after neostigmine was not significantly different from that after pyridostigmine. An overall incidence of cardiac dysrhythmias of 24 per cent was observed following the use of atropine by Owens, et al. ${ }^{3}$ with 64 per cent of all dysrhythmias occurring more than 30 minutes after reversal. In contrast, in the present study, only 25 per cent of dysrhythmias occurred after 30 minutes using glycopyrrolate, suggesting that the duration of its anticholinergic activity may be more appropriately matched to the time course of the two anticholinesterases.

A clinical diagnosis of pre-existing myocardial disease appears to be related to a high incidence 
of cardiac dysrhythmias. In this study, no patients who were free of known cardiovascular disorders had postoperative anticholinesteraserelated dysrhythmias, while more than onequarter of the patients with established cardiovascular disease had a new dysrhythmia within 90 minutes of reversal. To avoid the need for postoperative ventilatory support where possible, spontaneous recovery from neuromuscular blockade without the use of an anticholinesterase drug was not permitted. We have been unable to demonstrate a correlation between the incidence of dysrhythmias and the anaesthetic technique or the choice of muscle relaxants. In the neostigmine group, d-tubocurarine was selected for use in many more patients than was pancuronium, but the chi-square value for the appropriate contingency table did not indicate the difference in the relaxant used to be statistically significant.

We conclude that in geriatric patients with pre-existing cardiovascular disease the relatively long durations of action of neostigmine and pyridostigmine create a significant risk of cardiac muscarinic effects in the first 90 minutes following antagonism of neuromuscular blockade. Glycopyrrolate appears to minimize the greater cardiac muscarinic activity of neostigmine, as compared to pyridostigmine, noted in previous studies with atropine as part of the reversal mixture. Larger-scale studies will be required to determine whether glycopyrrolate should be considered the anticholinergic agent of choice for use in this high risk group of patients.

\section{SUMMARY}

The increase in cardiac muscarinic activity following injection of anticholinesterases can be minimized by the long-acting anticholinergic drug glycopyrrolate. In a series of 50 patients 65 years of age or older who had received glycopyrrolate $(0.88 \pm 0.15 \mathrm{mg})$ mixed with neostigmine $(4.40 \pm$ $0.66 \mathrm{mg})$ or pyridostigmine $(17.46 \pm 2.92 \mathrm{mg})$ to antagonize neuromuscular blockade, the incidence of new postoperative cardiac dysrhythmias was 16 per cent. All dysrhythmias occurred in patients with pre-existing cardiovascular disease. There was no statistically significant relationship between the incidence of cardiac dysrhythmias and the choice of anaesthetic technique or anticholinesterase drug.

\section{RÉSUMÉ}

L'augmentation de l'activité muscarinique cardiaque causée par l'injection d'un anticholinestérase peut être minimisée par un médicament anticholinergique de longue durée, le glycopyrrolate. Chez 50 malades ayant reçu du glycopyrrolate $(0.88 \pm 0.15 \mathrm{mg})$ mélangé à la néostigmine $(4.40 \pm 0.66 \mathrm{mg})$ ou à la pyridostigmine $(17.46 \pm 2.92 \mathrm{mg})$ pour renverser le blocage neuro-musculaire. l'incidence des dysrythmies cardiaques post-opératoires a été de 16 pour cent. Toutes ces dysrythmies sont survenues chez des malades qui présentaient déjà une maladie cardio-vasculaire. L'analyse statistique n'a pas révélé de rapport significatif entre l'incidence des troubles du rythme et la technique anesthésique ou le choix de l'anticholinestérase.

\section{REFERENCES}

1. Rosner, V., Kepes, E.R., \& Foldes, F.F. The effect of atropine and neostigmine on heart rate and rhythm. Br. J. Anaesth. 43: 1066 (1971).

2. KATZ, R.L. Pyridostigmin (Mestinon) as an antagonist of d-tubocurarine. Anesthesiology 28: 528 (1967).

3. Owens, W.D., Waldbaum, L.S., \& Stephen, C.R. Cardiac dysrhythmias following reversal of neuromuscular blocking agents in the geriatric patient. Anesth. Analg. 57: 186 (1978).

4. Miller, R.D., Von Nyhuis, L.S., Eger, E.I., VITEZ, T.S., \& WAY, W.L. Comparative times to peak effect and durations of action of neostigmine and pyridostigmine. Anesthesiology 41:27(1974).

5. Smith, C.M.. Mead, J.C., \& UnNa, K.R. Antagonism of d-tubocurarine III: time course of action of pyridostigmine, neostigmine, and edrophonium in vivo and in vitro. J. Pharm. Exp. Therap. 120:215 (1957).

6. Randall, L.O., Conroy, C.E., Ferriggia, T.M., KapPell, B.H., \& KNoepPel, C.R. Pharmacology of the anticholinesterase drugs: Mestinon, Prostigmin, Tensilon and TEPP. Am. J. Med. 19: 673 (1955).

7. Osserman, K.E. Progress report on mestinon bromide (pyridostigmin bromide). Am. J. Med. 19: 737 (1955).

8. Fogdall, R.P. \& Miller, R.D. Antagonism of d-tubocurarine and pancuronium induced neuromuscular blockade by pyridostigmine in man. Anesthesiology 39: 504 (1973). 